Received: 20 November 2017 Accepted: 20 December 2018 Published online: 08 February 2019
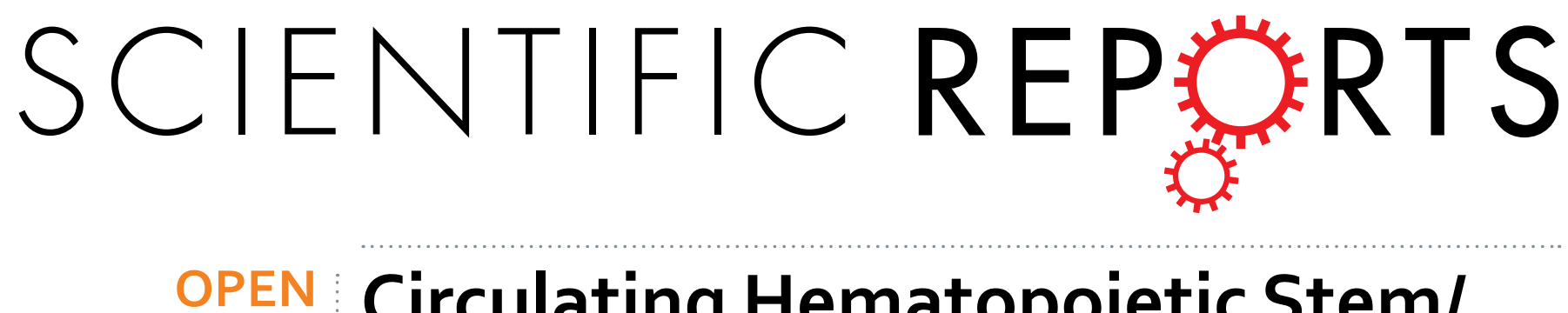

\section{Circulating Hematopoietic Stem/ Progenitor Cells are Associated with Coronary Stenoses in Patients with Coronary Heart Disease}

\author{
Fu-Li Zhu ${ }^{1}$, Ning Zhang ${ }^{2}$, Xiao-Juan $\mathrm{Ma}^{2}$, Jing Yang ${ }^{1}$, Wei-Ping Sun ${ }^{1}$, Yi-Oing Shen ${ }^{1}$, \\ Yu-Mei Wen ${ }^{1}$, Sha-Sha Yuan ${ }^{2}$, Dong Zhao ${ }^{2}$, Hai-Bin Zhang ${ }^{1}$ \& Ying-Mei Feng ${ }^{2}$
}

Inflammatory cells in atherosclerotic plaque exclusively originate from hematopoietic stem/progenitor cells (HSPCs). In this study, we investigated whether circulating HSPCs frequency related to coronary stenosis in patients with coronary heart disease (CHD). Coronary angiography was performed in 468 participants who were recruited at Cardiology Centre in LuHe Hospital from March 2016 to May 2017. Among these subjects, 344 underwent echocardiography. Mononuclear cells isolated from peripheral blood were stained with an antibody cocktail containing anti-human CD34, anti-human lineage, antihuman CD38, and anti-human CD45RA. Lineage ${ }^{-}$CD38 ${ }^{-}$CD45RA ${ }^{\operatorname{dim}}$ CD34 ${ }^{+}$HSPCs were quantified by flow cytometry. CHD was defined as coronary stenosis $\geq \mathbf{5 0 \%}$ and the extent of CHD was further categorised by coronary stenosis $\geq 70 \%$. A $p<0.0031$ was regarded statistically significant by the Bonferroni correction. Circulating HSPCs frequency was 1.8 -fold higher in CHD patients than non-CHD participants $(p=0.047)$. Multivariate-adjusted logistic analysis demonstrated that HSPCs was the only marker that was associated with the odds ratio of having mild vs. severe coronary stenosis (2.08 $(95 \% \mathrm{Cl}, 1.35-3.21), \mathrm{p}=0.0009)$. Left ventricular ejection fraction was inversely correlated with HSPCs frequency and CRP in CHD patients ( $<<0.05$ for both). In conclusion, HSPCs frequency in circulation is intimately related to coronary stenoses in CHD patients.

Atherosclerosis forms the pathological basis of coronary heart disease $(\mathrm{CHD})^{1}$. The initiation and progression of atherosclerosis are complicated, involving endothelial dysfunction, inflammation, oxidative stress and thrombus formation ${ }^{2-4}$. Risk factors such as hypercholesterolemia and diabetes enhance endothelial cell injury and inflammation and reinforce atherosclerosis progression in mice ${ }^{5-7}$ and humans ${ }^{8,9}$. Despite the implementation of various regimens having had beneficial effects in CHD patients, a large number of patients still progress to repeated stenting for revascularisation and recurrent myocardial infarction ${ }^{2}$. Therefore, the screening and identification of novel markers that reflect the severity of coronary stenosis are needed not only for assessing CHD but also for establishing therapeutic targets for treating this disease.

Inflammatory cell infiltration and foam cell formation are hallmarks of atherosclerosis progression ${ }^{10-12}$. Amplification of the inflammatory cell cascade and the production of inflammatory cytokines and chemokines accelerate coronary stenoses and plaque rupture, resulting in acute coronary syndrome and myocardial infarction. Inflammatory cells are known to be exclusively derived from hematopoietic stem/progenitor cells (HSPCs) in bone marrow. In line with the literature ${ }^{13,14}$, we recently reported experimental studies that showed that hypercholesterolemia and low-density lipoproteins enhance the proliferation of HSPCs and their subsequent differentiation to atherogenic neutrophils and monocytes, whereas high-density lipoproteins inhibit these processes ${ }^{15,16}$. In this study, we moved from analyses of mice to human subjects to confirm that HSPCs in circulation could be associated with coronary stenoses.

${ }^{1}$ Department of Cardiology, Beijing LuHe Hospital, Capital Medical University, Beijing, China. ${ }^{2}$ Beijing Key Laboratory of Diabetes Prevention and Research, Department of Endocrinology, Beijing LuHe Hospital, Capital Medical University, Beijing, China. Fu-Li Zhu, Ning Zhang and Xiao-Juan Ma contributed equally. Correspondence and requests for materials should be addressed toY.-M.F. (email: yingmeif13@sina.com) 


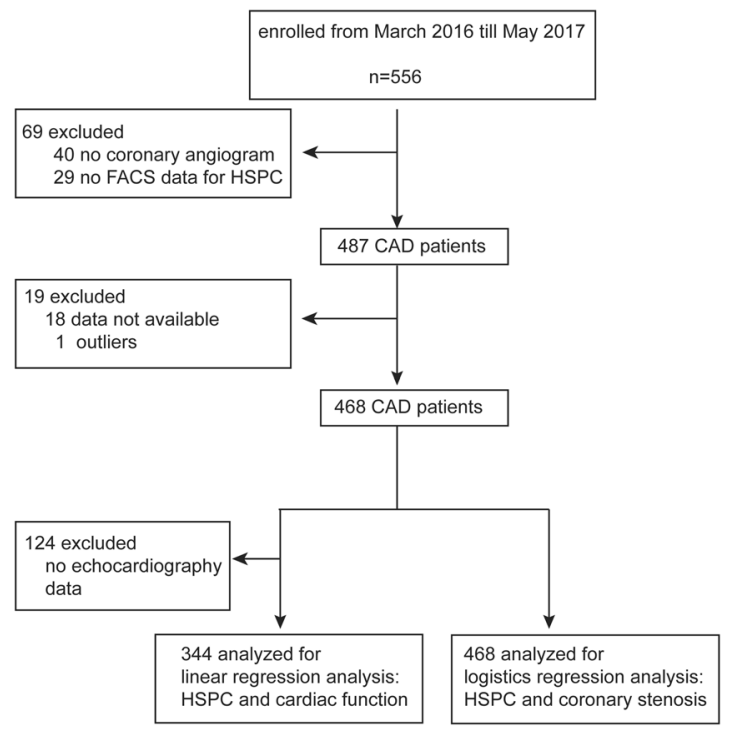

Figure 1. Flowchart. HSPCs, hematopoietic stem/progenitor cells.

\section{Results}

Characteristics of CAD patients. From March 2016 to May 2017, 556 patients were enrolled in this study. Flowchart of the participants included in the analysis is shown in Fig. 1. Among the 468 CHD patients, $195(41.7 \%)$ were women. Mean values $( \pm S D)$ in these 468 participants were $60.9 \pm 10.5$ years for age, $134.1 \pm 17.5 \mathrm{mmHg}$ and $79.8 \pm 11.2 \mathrm{mmHg}$ for systolic and diastolic blood pressure, and $4.33 \pm 0.99 \mathrm{mmol} / \mathrm{L}$ for total cholesterol. Among all participants, 294 (62.8\%) had hypertension, of whom 237 (50.6\%) were on antihypertensive drugs, and 125 (26.7\%) had diabetes.

All patients were examined by coronary angiography for stenoses of four coronary arteries, namely, left main artery, anterior descending branch, left circumflex and right coronary artery. Coronary stenoses was calculated as plaque area divided by lumen area and multiplied by 100 . Subjects were diagnosed with CHD if coronary stenoses were equal to or above 50 in any of the coronary arteries based on coronary angiography. Table 1 lists the general characteristics of the subjects with and without CHD.

Based on the presence of significant stenoses $(\geq 70 \%)$, the CHD patients were categorised into three groups: mild, if the stenosis of all coronary arteries was less than 70\%; medium, if the stenosis of one of the coronary arteries was equal to or above $70 \%$; and severe, if the stenosis of two or more of the coronary arteries was equal to or above $70 \%$ (Fig. 2A,B). Table 2 lists the general characteristics of the subjects by the severity of coronary artery occlusion in CHD patients. Serum LDL-c levels in patients with medium coronary stenosis were higher than those in patients with mild coronary stenosis (Table 2). Although serum levels of GM-CSF, SDF-1 $\alpha$, fibrinogen and D-dimer did not differ among the groups, neutrophil count was greater in patients with medium and severe coronary stenosis than in those with mild stenosis (medium vs. mild: $5.35 \pm 2.56 \times 10^{9} / \mathrm{L}$ vs. $4.38 \pm 1.51 \times 10^{9} / \mathrm{L}$, $\mathrm{p}=0.004$; severe vs. mild: $5.15 \pm 2.52 \times 10^{9} / \mathrm{L}$ vs. $\left.4.38 \pm 1.51 \times 10^{9} / \mathrm{L}, \mathrm{p}=0.018\right)($ Table 2$)$.

Coronary artery stenosis. Human HSPCs are included in the CD $34^{+} \mathrm{CD}_{3} 8^{-} \mathrm{CD} 45 \mathrm{RA}^{\mathrm{dim}}$ lineage $^{-}$cell population ${ }^{16,17}$. When $\mathrm{CD} 34^{+} \mathrm{CD} 38^{-} \mathrm{CD} 45 \mathrm{RA}^{\text {dimlineage }}{ }^{-} \mathrm{HSPCs}$ were plated for a colony-forming assay and differentiated in vitro, they formed myeloid colonies as evidenced by the percentage of CD11b+cells by FACS analysis (CD11b + cells $\%$ in un-differentiated HSPCs vs. differentiated HSPCs: $0.02 \pm 0.01 \%$ vs. $48.67 \pm 8.61 \%, \mathrm{p}=0.012, \mathrm{n}=3$ for each) (Fig. 2C,D). FACS analysis illustrated that the proportion of circulating $\mathrm{CD} 34^{+} \mathrm{CD}^{-} 8^{-} \mathrm{CD} 45 \mathrm{RA}^{\mathrm{dim}}$ lineage ${ }^{-}$HSPCsamong mononuclear cells was higher in CHD patients than in non-CHD patients $(0.10 \%$ vs. $0.08 \%, \mathrm{p}=0.047)$ (Table 1$)$. Moreover, the HSPCs frequency was $0.06 \%$ in the group with mild coronary stenosis, but increased to $0.10 \%$ in the medium and $0.11 \%$ in the severe coronary stenosis groups ( $\mathrm{p}<0.05$ for both) (Table 2, Fig. 2E,F). Representative FACS plots showed how HSPCs were analysed by flow cytometry (Fig. 2G-I). By Spearman's analysis, HSPCs frequency was shown to be positively associated with white blood cell and neutrophil counts in CHD patients (white blood cell count: $r=0.13, p=0.022$; neutrophil count: $r=0.15, p=0.008$ ) (Fig. 2J,K) but not in non-CHD participants $(p \geq 0.42)$. By contrast, circulating HSPCs frequency was not associated with differential lymphocyte count in those with or without $\mathrm{CHD}(\mathrm{p} \geq 0.20)$.

Categorical analysis. We first compared the relationship of each marker with the occurrence of CHD. When adjusting for cofounding factors, for a one-SD increase for each of the following variables, the odds ratio of having CHD vs. no CHD was 1.24 (95\% CI, 1.07-1.48; $\mathrm{p}=0.017)$ for HSPCs, 1.48 (95\% CI, $1.23-1.79 ; \mathrm{p}<0.0001)$ for CRP, 1.22 (95\% CI, 1.01-1.47; $\mathrm{p}=0.043)$ for white blood cell count, 1.26 (95\% CI, $1.05-1.53 ; \mathrm{p}=0.016)$ for neutrophil count and 1.33 (95\% CI, 1.12-1.60; $\mathrm{p}=0.002)$ for low-density lipoprotein cholesterol (LDL-c) (Table 3). After Bonferroni correction for 16 biomarkers, the odds ratio of having no CHD vs. CHD remained significantly associated with serum CRP and LDL-c $(\mathrm{p}<0.0031)$. 


\begin{tabular}{|c|c|c|c|}
\hline Characteristic & No CHD & CHD & P value \\
\hline Number in category & 154 & 314 & \\
\hline \multicolumn{4}{|l|}{ Number of subjects (\%) } \\
\hline Women & $83(53.9)$ & $112(35.7)$ & $<0.0001$ \\
\hline Smokers & $52(33.8)$ & $165(52.5)$ & $<0.0001$ \\
\hline Drinking alcohol & $31(20.1)$ & $96(30.6)$ & 0.020 \\
\hline Hypertension & $88(57.1)$ & $206(65.6)$ & 0.084 \\
\hline Antihypertensive treatment & $93(60.4)$ & $247(78.7)$ & $<0.0001$ \\
\hline dyslipidemia & $113(73.4)$ & $252(80.3)$ & 0.092 \\
\hline Statins treatment & $110(71.4)$ & $266(84.7)$ & 0.001 \\
\hline Diabetes mellitus & $29(18.8)$ & $96(30.6)$ & 0.008 \\
\hline \multicolumn{4}{|l|}{ Mean (SD) of characteristic } \\
\hline Age (years) & $59.8(10.1)$ & $61.4(10.6)$ & 0.10 \\
\hline Systolic pressure $(\mathrm{mm} \mathrm{Hg})$ & $132.4(16.2)$ & $134.9(18.0)$ & 0.13 \\
\hline Diastolic pressure $(\mathrm{mm} \mathrm{Hg})$ & $79.6(8.9)$ & $79.9(12.2)$ & 0.75 \\
\hline Mean arterial pressure $(\mathrm{mm} \mathrm{Hg})$ & $97.2(9.7)$ & $98.2(12.6)$ & 0.31 \\
\hline Heart rate (beats per minute) & $71.2(11.5)$ & $74.8(12.8)$ & 0.004 \\
\hline \multicolumn{4}{|l|}{ Biochemical data } \\
\hline Serum creatinine $(\mu \mathrm{mol} / \mathrm{L})$ & $74(61-84)$ & $74(64-84)$ & 0.96 \\
\hline eGFR $\left(\mathrm{mL} / \mathrm{min} / 1.73 \mathrm{~m}^{2}\right)$ & $86.4(19.0)$ & $87.5(16.7)$ & 0.53 \\
\hline Plasma glucose $(\mathrm{mmol} / \mathrm{L})$ & $5.68(1.40)$ & $6.48(2.90)$ & $<0.0001$ \\
\hline$\gamma$-glutamyltransferase (units/L) & $22(17-31)$ & $24(17-35)$ & 0.10 \\
\hline uric acid $(\mu \mathrm{mol} / \mathrm{L})$ & $340.9(97.3)$ & $331.9(87.5)$ & 0.31 \\
\hline Serum triglyceride $(\mathrm{mmol} / \mathrm{L})$ & $1.31(0.95-1.89)$ & $1.51(1.07-2.07)$ & 0.17 \\
\hline Total cholesterol $(\mathrm{mmol} / \mathrm{L})$ & $4.26(0.94)$ & $4.37(1.01)$ & 0.26 \\
\hline LDL cholesterol $(\mathrm{mmol} / \mathrm{L})$ & $2.69(0.79)$ & $2.82(0.88)$ & 0.19 \\
\hline HDL cholesterol (mmol/L) & $1.09(0.30)$ & $1.05(0.24)$ & 0.056 \\
\hline Apolipoprotein A-I $(\mu \mathrm{g} / \mathrm{mL})$ & $8.84(2.09)$ & $8.82(2.04)$ & 0.95 \\
\hline Apolipoprotein B $(\mu \mathrm{g} / \mathrm{mL})$ & $203.0(46.7)$ & $202.0(50.1)$ & 0.84 \\
\hline \multicolumn{4}{|l|}{ Inflammatory markers } \\
\hline White blood cell count $\left(\mathrm{x} 10^{9} / \mathrm{L}\right)$ & $6.92(1.7)$ & $7.7(2.7)$ & 0.001 \\
\hline Neutrophils (x109/L) & $4.33(1.46)$ & $5.13(2.44)$ & $<0.0001$ \\
\hline Lymphocytes $\left(\mathrm{x} 10^{9} / \mathrm{L}\right)$ & $1.91(0.68)$ & $1.86(0.77)$ & 0.49 \\
\hline Monocytes $\left(\mathrm{x} 10^{9} / \mathrm{L}\right)$ & $0.47(0.15)$ & $0.50(0.20)$ & 0.077 \\
\hline C-reactive protein $(\mathrm{mg} / \mathrm{L})$ & $0.96(0.70-1.60)$ & $1.56(0.89-4.88)$ & $<0.0001$ \\
\hline GM-CSF(ng/L) & $107.4(21.7)$ & $108.3(22.2)$ & 0.70 \\
\hline SDF- $1 \alpha(\mathrm{pg} / \mathrm{mL})$ & $3579.2(674.9)$ & $3562.3(648.1)$ & 0.79 \\
\hline \multicolumn{4}{|l|}{ Coagulation markers } \\
\hline Fibrinogen $(\mathrm{g} / \mathrm{L})$ & $3.03(2.60-3.43)$ & $3.13(2.69-3.58)$ & 0.19 \\
\hline D-dimer (mg/L) & $0.09(0.06-0.15)$ & $0.11(0.07-0.18)$ & 0.11 \\
\hline Circulating HSPCs (\%) & $0.08(0.03-0.10)$ & $0.10(0.04-0.12)$ & 0.047 \\
\hline
\end{tabular}

Table 1. Characteristics of the participants. CHD, defined by coronary artery stenosis $\geq 50 \%$ as determined by coronary angiography. HSPCs: hematopoietic stem/progenitor cells. Logarithmically transformed values are expressed as geometric means (interquartile range). Means were compared using $t$-test and proportions by Fisher's exact test.

Among CHD patients, for a one-SD increase in each of the following variables, the multivariable-adjusted odds ratios expressing the risk of having medium coronary artery stenosis $\geq 70 \%$ vs. $50-70 \%$ were 1.72 (95\% CI, $1.17-2.54 ; \mathrm{p}=0.006)$ for HSPCs, $1.36(95 \% \mathrm{CI}, 0.88-2.14, \mathrm{p}=0.17)$ for CRP, 1.57 (95\% CI, 0.94-2.63, $\mathrm{p}=0.09)$ for white blood cell count, $1.62(95 \% \mathrm{CI}, 0.94-2.80 ; \mathrm{p}=0.10)$ for neutrophil count and 2.08 (95\% CI, $1.20-3.62$; $\mathrm{p}=0.023$ ) for LDL-c (Table 3). Similarly, multivariate-adjusted logistic analysis demonstrated that, for a one-SD increase, the odds ratios expressing the risk of having severe coronary stenosis $\geq 70 \%$ vs. mild coronary stenosis $<70 \%$ were 2.08 (95\% CI, 1.35-3.21; $\mathrm{p}=0.0009)$ for HSPCs, 1.67 (95\% CI, 1.06-2.62, $\mathrm{p}=0.026$ ) for CRP, 2.45 (95\% CI, 0.86-2.21, $\mathrm{p}=0.18)$ for white blood cell count, 1.47 (95\% CI, 0.88-2.44; $\mathrm{p}=0.15)$ for neutrophil count and 1.67 (95\% CI, 1.11-2.51, $\mathrm{p}=0.014)$ for LDL-c (Table 3). Nevertheless, neither HSPCs frequency nor other markers were associated with the risk of having medium $v$ s. severe stenosis $(\mathrm{p} \geq 0.05)$ (Table 3$)$. After Bonferroni correction, HSPCs was the only marker that was associated with the odds ratio of having mild $v s$. severe coronary stenosis $(\mathrm{p}<0.0031)$ whereas none of these markers was associated with the odds ratio of having mild $v s$. medium coronary stenosis. 


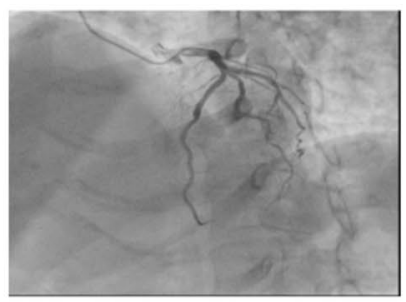

$\mathrm{C}$

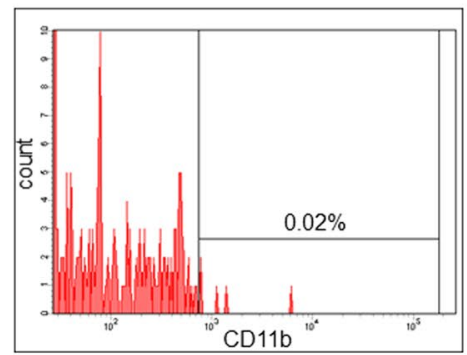

$\mathrm{E}$

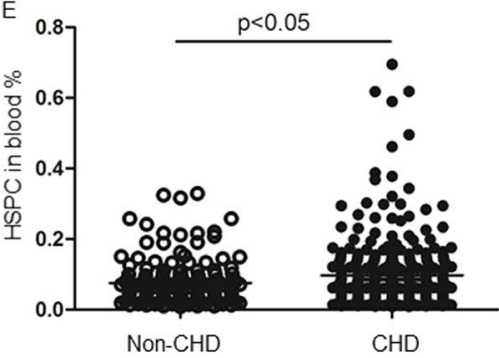

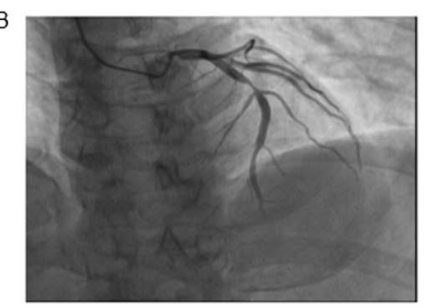

$\mathrm{D}$

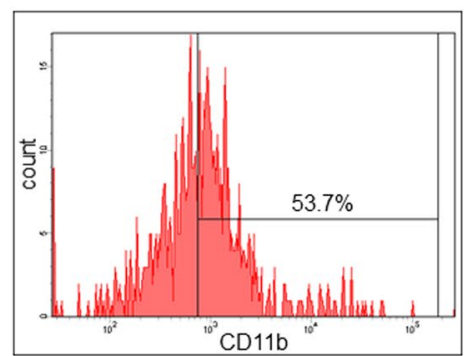

F

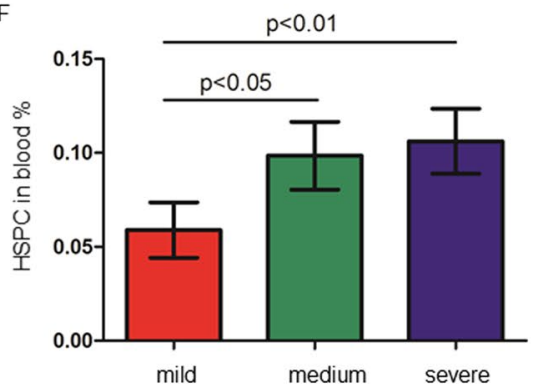

G

H

।
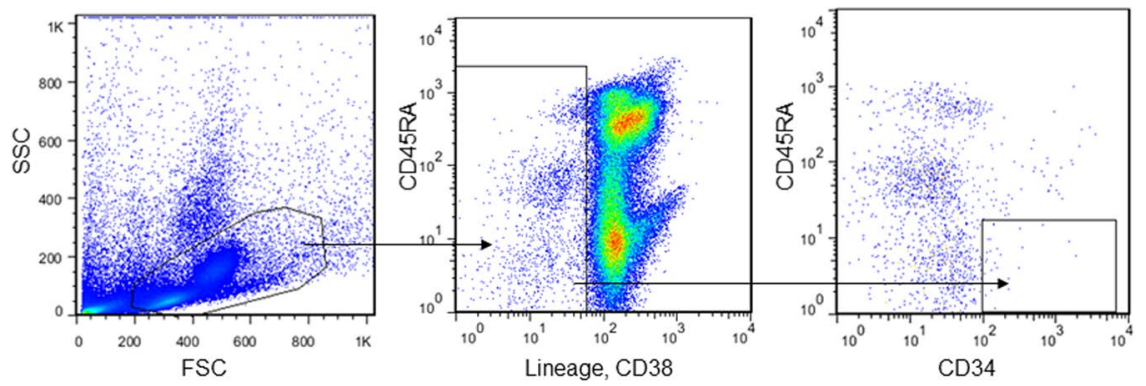

J

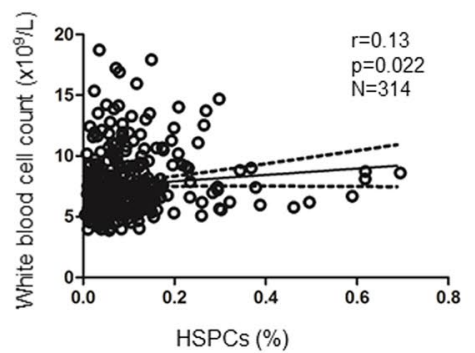

K

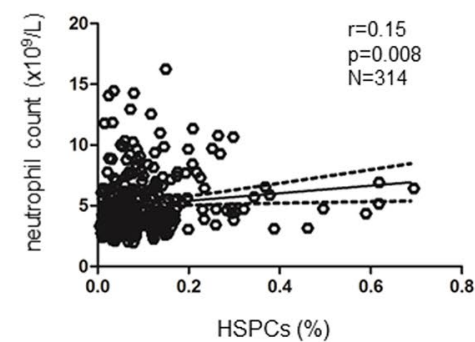

Figure 2. HSPCs frequency in CHD patients. Mild coronary stenosis $<50 \%(\mathrm{~A})$ and severe coronary stenosis $\geq 70 \%$ (B), as detected by coronary angiography. (C) The percentage of CD11b + cells in freshly isolated HSPCs (C). (D) HSPCs were plated on Methylcelluose cultures for 14 days. Cells were harvested and stained with anti-human CD11b. The percentage of CD11b+ cells was shown. (E) HSPCs frequency in subjects with and without CHD. (F) HSPCs frequency in CAD with different extents of stenosis. HSPCs frequencies in e and fare expressed as mean and 95\% CI. (G-I) Representative FACS plot of HSPCs analysis. Among all samples, at least8728 (95\%CI, 5783-11674) CD34+ cells were obtained in the analysis. (J,K) The correlation curves of HSPCs frequency and white blood cell count or neutrophil count in CHD patients, respectively. 


\begin{tabular}{|c|c|c|c|}
\hline \multirow[b]{2}{*}{ Characteristic } & \multicolumn{3}{|c|}{ Coronary artery stenoses } \\
\hline & mild & medium & severe \\
\hline Number in category & 41 & 132 & 141 \\
\hline \multicolumn{4}{|l|}{ Number of subjects (\%) } \\
\hline Women & $18(43.9)$ & $46(34.8)$ & $48(34.0)$ \\
\hline Smokers & $12(29.3)$ & 77 (58.3) & $76(53.9)$ \\
\hline Drinking alcohol & $11(26.8)$ & $44(33.3)$ & $41(29.1)$ \\
\hline Hypertension & $28(68.3)$ & 84 (63.6) & $94(66.7)$ \\
\hline Antihypertensive treatment & $34(82.9)$ & $99(75.0)$ & $114(80.9)$ \\
\hline Dyslipidemia & $113(73.4)$ & $106(80.3)$ & $115(81.6)$ \\
\hline Statins treatment & $33(80.5)$ & $114(86.4)$ & $119(84.4)$ \\
\hline Diabetes mellitus & $19(46.3)$ & $26(19.7)$ & $51(36.2)$ \\
\hline Myocardial infarction & $3(13.1)$ & $24(42.9)$ & $29(51.8)$ \\
\hline \multicolumn{4}{|l|}{ Mean (SD) of characteristic } \\
\hline Age (years) & $62.0(8.2)$ & $59.6(10.5)$ & $63.0(11.1)$ \\
\hline Systolic pressure (mm Hg) & $138.8(16.9)$ & $134.4(19.5)$ & $134.3(16.8)$ \\
\hline Diastolic pressure $(\mathrm{mm} \mathrm{Hg})$ & $80.9(11.0)$ & $80.1(13.0)$ & $79.3(11.9)$ \\
\hline Mean arterial pressure $(\mathrm{mm} \mathrm{Hg})$ & $100.2(11.8)$ & $98.2(13.5)$ & $97.6(11.9)$ \\
\hline Heart rate (beats per minute) & $76.0(12.5)$ & $74.8(14.4)$ & $74.5(11.2)$ \\
\hline \multicolumn{4}{|l|}{ Biochemical data } \\
\hline Serum creatinine $(\mu \mathrm{mol} / \mathrm{L})$ & $71(59-76)$ & $72(63-83)$ & $78(66-88)^{\dagger}$ \\
\hline eGFR $\left(\mathrm{mL} / \mathrm{min} / 1.73 \mathrm{~m}^{2}\right)$ & $90.8(13.1)$ & $90.2(16.1)$ & $83.9(17.6)^{\dagger}$ \\
\hline Serum triglyceride $(\mathrm{mmol} / \mathrm{L})$ & $1.58(0.92-2.12)$ & $1.57(1.12-2.18)$ & $1.48(0.99-1.92)$ \\
\hline Total cholesterol $(\mathrm{mmol} / \mathrm{L})$ & $3.98(0.76)$ & $4.46(0.93)^{\dagger}$ & $4.40(1.13)^{\dagger}$ \\
\hline LDL cholesterol $(\mathrm{mmol} / \mathrm{L})$ & $2.48(0.70)$ & $2.88(0.78)^{\dagger}$ & $2.85(0.98)^{*}$ \\
\hline HDL cholesterol $(\mathrm{mmol} / \mathrm{L})$ & $1.00(0.22)$ & $1.08(0.27)$ & $1.03(0.20)$ \\
\hline Fasting blood glucose $(\mathrm{mmol} / \mathrm{L})$ & $6.74(2.34)$ & $6.12(2.46)$ & $6.74(3.35)$ \\
\hline$\gamma$-glutamyltransferase (units/L) & $21(15-31)$ & $26(20-37)$ & $22(16-32)$ \\
\hline uric acid $(\mu \mathrm{mol} / \mathrm{L})$ & $304.5(84.5)$ & $327.4(82.6)$ & $344.1(91.2)^{*}$ \\
\hline Apolipoprotein A-I $(\mu \mathrm{g} / \mathrm{mL})$ & $8.90(1.85)$ & $8.65(2.01)$ & $8.97(2.11)$ \\
\hline Apolipoprotein B $(\mu \mathrm{g} / \mathrm{mL})$ & $200.9(45.3)$ & $200.0(51.7)$ & $204.2(50.1)$ \\
\hline \multicolumn{4}{|l|}{ Inflammation markers } \\
\hline HSPC (\%) & $0.04(0.03-0.09)$ & $0.07(0.03-0.13)^{\dagger}$ & $0.07(0.04-0.14) \S$ \\
\hline C-reactive protein $(\mathrm{mg} / \mathrm{L})$ & $1.10(0.79-2.98)$ & $1.56(0.90-4.59)$ & $1.90(0.90-6.20)^{*}$ \\
\hline GM-CSF (ng/L) & $105.5(21.7)$ & $107.6(21.9)$ & $109.7(22.7)$ \\
\hline SDF-1 $\alpha(\mathrm{pg} / \mathrm{mL})$ & $3530.7(612.6)$ & $3553.9(657.1)$ & $3579.3(653.6)$ \\
\hline WBC count $\left(\mathrm{x} 10^{9} / \mathrm{L}\right)$ & $6.85(1.91)$ & $7.97(2.83)^{\dagger}$ & $7.68(2.72)$ \\
\hline Neutrophils $\left(\mathrm{x} 10^{9} / \mathrm{L}\right)$ & $4.38(1.51)$ & $5.35(2.56)^{\dagger}$ & $5.15(2.52)^{*}$ \\
\hline Monocytes $\left(\mathrm{x} 10^{9} / \mathrm{L}\right)$ & $0.48(0.22)$ & $0.50(0.20)$ & $0.50(0.19)$ \\
\hline Lymphocytes $\left(\mathrm{x} 10^{9} / \mathrm{L}\right)$ & $1.77(0.54)$ & $1.92(0.89)$ & $1.83(0.71)$ \\
\hline \multicolumn{4}{|l|}{ Coagulation markers } \\
\hline Fibrinogen $(\mathrm{g} / \mathrm{L})$ & $2.93(2.42-3.26)$ & $3.13(2.73-3.57)$ & $3.20(2.69-3.70)$ \\
\hline D-dimer (mg/L) & $0.11(0.07-0.16)$ & $0.10(0.06-0.16)$ & $0.11(0.07-0.19)$ \\
\hline Circulating HSPCs (\%) & $0.06(0.02-0.07)$ & $0.10(0.03-0.13) *$ & $0.11(0.04-0.14)$ \\
\hline
\end{tabular}

Table 2. Characteristics of CHD patients by coronary stenosis severity. The extent of CHD was defined by the number of significant coronary artery stenoses. Myocardial infarction included both ST-elevated and nonST-elevated myocardial infarction. eGFR: estimated glomerular filtration rate. HSPCs: hematopoietic stem/ progenitor cells. Logarithmically transformed values are expressed as geometric means (interquartile range). Means were compared using $t$-test and ANOVA and proportions by Fisher's exact test. Significance of the difference when compared with the mild group: ${ }^{*} P \leq 0.05 ;{ }^{\dagger} P \leq 0.01$.

When we pooled non-CHD subjects and CHD patients together, the V-plot confirmed the results of logistic analyses (Table 3) by showing that HSPCs, CRP, white blood cell count, neutrophil count and LDL-c were associated with significant coronary stenosis $\geq 70 \%$ vs. $<70 \%$ (Fig. 3 ).

ROC. CRP is a general inflammatory marker related to inflamed atherosclerotic plaque. The area under the curve (AUC) for CRP in the discrimination between stenosis $<70 \%$ and $\geq 70 \%$ was 0.64 (95\% CI, 0.59-0.69) in all subjects. Using CRP as a reference (Fig. 4), the AUC values of HSPCs, white blood cell count and LDL-c were 


\begin{tabular}{|c|c|c|c|c|}
\hline \multirow[b]{2}{*}{ Coronary occlusion severity } & No CHD cs. CHD & CHD & CHD & CHD \\
\hline & $<50 \%$ vs $\geq 50 \%$ & Mild vs. medium & Mild vs. severe & Medium vs. severe \\
\hline \multicolumn{5}{|l|}{ Inflammation markers } \\
\hline $\operatorname{HSPC}(\%)$ & 1.24 (1.04 to 1.48$)$ & $1.72(1.17$ to 2.54$)$ & $2.08(1.35 \text { to } 3.21)^{\ddagger}$ & $1.07(0.83$ to 1.38$)$ \\
\hline C-reactive protein $(\mathrm{mg} / \mathrm{L})$ & $1.48(1.23 \text { to } 1.79)^{\varsigma}$ & $1.37(0.88$ to 2.14$)$ & $1.67(1.06$ to 2.62$)$ & $1.22(0.94$ to 1.58$)$ \\
\hline GM-CSF (ng/L) & $1.07(0.90$ to 1.27$)$ & $1.09(0.72$ to 1.65$)$ & $1.33(0.92$ to 1.96$)$ & $1.12(0.88$ to 1.45$)$ \\
\hline SDF-1 $\alpha(\mathrm{pg} / \mathrm{mL})$ & $1.00(1.00$ to 1.00$)$ & $1.00(0.52$ to 1.93$)$ & $1.00(1.00$ to 1.00$)$ & $1.00(1.00$ to 1.00$)$ \\
\hline White blood cells & $1.22(1.01$ to 1.47$)$ & $1.57(0.94$ to 2.63$)$ & $1.38(0.86$ to 2.21$)$ & $0.91(0.70$ to 1.17$)$ \\
\hline Neutrophils (x109/L) & $1.27(1.04$ to 1.53$)$ & $1.62(0.94$ to 2.80$)$ & $1.47(0.88$ to 2.44$)$ & $0.93(0.73$ to 1.18$)$ \\
\hline Monocytes $\left(\mathrm{x} 10^{9} / \mathrm{L}\right)$ & $1.06(0.88$ to 1.27$)$ & $0.99(0.99$ to 1.00$)$ & $0.89(0.61$ to 1.32$)$ & $1.04(0.81$ to 1.34$)$ \\
\hline Lymphocytes $\left(\times 10^{9} / \mathrm{L}\right)$ & $0.97(0.81$ to 1.16$)$ & $1.14(0.77$ to 1.70$)$ & $1.03(0.65$ to 1.62$)$ & $0.93(0.73$ to 1.20$)$ \\
\hline \multicolumn{5}{|l|}{ Coagulation markers } \\
\hline Fibrinogen $(\mathrm{g} / \mathrm{L})$ & $0.95(0.80$ to 1.13$)$ & $1.07(0.74$ to 1.55$)$ & $0.99(0.64$ to 1.52$)$ & $1.04(0.78$ to 1.39$)$ \\
\hline $\mathrm{D}$-dimer $(\mathrm{mg} / \mathrm{L})$ & $1.13(0.95$ to 1.35$)$ & $1.03(0.75$ to 1.55$)$ & $0.92(0.64$ to 1.33$)$ & $1.04(0.79$ to 1.37$)$ \\
\hline \multicolumn{5}{|l|}{ Lipids and metabolism markers } \\
\hline Serum triglyceride $(\mathrm{mmol} / \mathrm{L})$ & $1.02(0.85$ to 1.23$)$ & $1.24(0.77$ to 2.01$)$ & $0.94(0.70$ to 1.26$)$ & $0.74(0.54$ to 1.01$)$ \\
\hline LDL-cholesterol (mmol/L) & $1.33(1.12 \text { to } 1.60)^{\dagger}$ & $2.09(1.20$ to 3.62$)$ & $1.67(1.11$ to 2.51$)$ & $1.00(0.70$ to 1.43$)$ \\
\hline HDL-cholesterol (mmol/L) & $0.91(0.76$ to 1.09$)$ & $1.65(1.03$ to 2.64$)$ & $1.34(0.78$ to 2.28$)$ & $0.80(0.57$ to 1.12$)$ \\
\hline Apolipoprotein A-1 $(\mu \mathrm{g} / \mathrm{mL})$ & $1.06(0.89$ to 1.26$)$ & $0.98(0.65$ to 1.47$)$ & $0.95(0.64$ to 1.40$)$ & $1.16(0.90$ to 1.51$)$ \\
\hline Apolipoprotein B $(\mu \mathrm{g} / \mathrm{mL})$ & $0.95(0.82$ to 1.16$)$ & $1.05(0.71$ to 1.55$)$ & $1.05(0.71$ to 1.55$)$ & $1.00(0.78$ to 1.28$)$ \\
\hline Uric acid $(\mu \mathrm{mol} / \mathrm{L})$ & $1.00(0.83$ to 1.27$)$ & $1.10(0.69$ to 1.72$)$ & $1.44(0.91$ to 2.26$)$ & $1.31(0.91$ to 1.72$)$ \\
\hline
\end{tabular}

Table 3. Multivariable-adjusted associations of coronary occlusion status with biomarkers. All analyses were adjusted for covariables, including age, sex, mean arterial pressure, heart rate, plasma glucose, serum creatinine, plasma glucose, $\gamma$-glutamyltransferase, smoking, alcohol intake, history of hypertension ( 1 or 0 ), history of diabetes ( 1 or 0$)$, use of diuretics, inhibitors of the renin-angiotensin system ( $\beta$-blockers, angiotensin-converting-enzyme inhibitors and angiotensin type- 1 receptor blockers), vasodilators (calciumchannel blockers and $\alpha$-blockers), metformin and statins. With the exceptions of LDL-c and HDL-c, all other biomarkers were additionally adjusted with the total-to-HDL cholesterol ratio. A value of $P<0.0031$ was considered significant after the Bonferroni correction. Significance of the associations: ${ }^{\dagger} P<0.01 ;{ }^{\ddagger} P<0.001$; ${ }^{\S} P \leq 0.0001$.

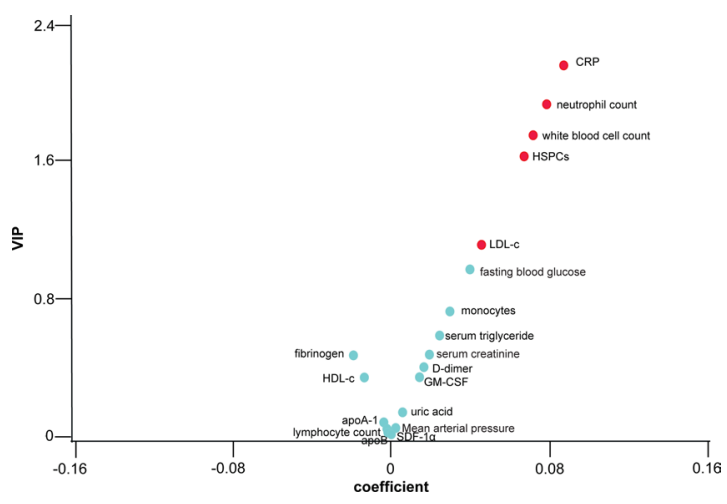

Figure 3. We divided the study population of 468 participants using coronary artery stenosis and circulating biomarkers. V-plots were generated for the PLS-DA-derived VIP scores versus the centred and rescaled correlation coefficients. HSPCs, neutrophils, lymphocytes and monocytes are expressed as percentages among white blood cells. HSPCs, CRP, serum triglyceride, fibrinogen and D-dimer were logarithmically transformed in the analysis. VIP represents the importance of each marker in the construction of the PLS factors. The correlation coefficients reflect the association of significant coronary stenosis ( $\geq 70 \%)$ with each marker. The markers with VIP score $\geq 1$ and VIP score $<1$ are indicated in red and cyan blue, respectively.

0.60 (95\% CI, 0.54-0.65; $\mathrm{p}=0.21), 0.58(95 \% \mathrm{CI}, 0.53-0.64 ; \mathrm{p}=0.072)$ and $0.56(95 \% \mathrm{CI}, 0.51-0.61, \mathrm{p}=0.022)$, respectively. These data suggest that HSPCs, white blood cell count and CRP were equally potent at discriminating significant coronary stenosis.

Cardiac function by echocardiography. Finally, we analysed the relationship between these biomarkers and cardiac function. Among all subjects, 344 were examined by echocardiography. Left ventricular ejection fraction, end-systolic diameter and end-diastolic diameter did not differ between non-CHD subjects and CHD patients (Table 4 ). 


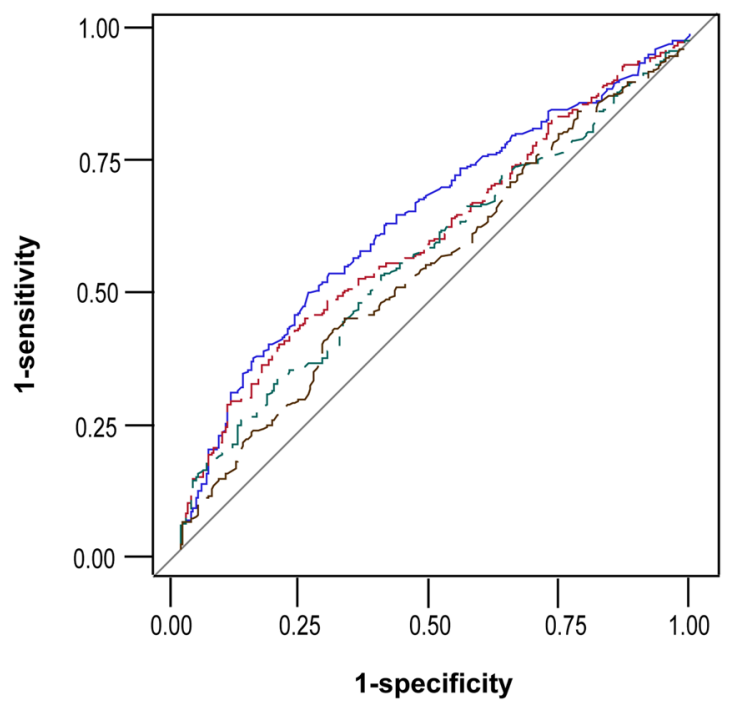

Figure 4. Receiver operating characteristic (ROC) curves for prediction of significant coronary stenosis (from $<70 \%$ to $\geq 70 \%$ ). Blue, red, green and black lines identify C-reactive protein, HSPCs, white blood cell count and LDL-cholesterol, respectively.

\begin{tabular}{|l|l|l|l|}
\hline Characteristic & Non-CHD & CHD & P value \\
\hline Number in category & 92 & 252 & \\
\hline Women (\%) & $52(56.5 \%)$ & $95(37.7 \%)$ & \\
\hline Mean (SD) of characteristic & $9.77(1.51)$ & $10.19(1.69)$ & 0.062 \\
\hline Left ventricular post wall (mm) & $49.26(4.55)$ & $49.72(5.60)$ & 0.439 \\
\hline Left ventricular diastolic diameter $(\mathrm{mm})$ & $30.42(5.31)$ & $31.12(6.44)$ & 0.354 \\
\hline Left ventricular systolic diameter $(\mathrm{mm})$ & $9.08(3.42)$ & $8.09(2.59)$ & 0.010 \\
\hline Movement range of interventricular septal $(\mathrm{mm})$ & $11.34(2.36)$ & $11.12(2.41)$ & 0.517 \\
\hline Movement range of left ventricular post wall $(\mathrm{mm})$ & $68.22(8.97)$ & $67.08(10.31)$ & 0.347 \\
\hline Ejection fraction $(\%)$ & & & \\
\hline
\end{tabular}

Table 4. Characteristics of the study participants. CHD, coronary heart disease. Data are expressed as mean (SD). Means were compared using $t$-test between two groups.

Multivariate-adjusted linear regression analysis demonstrated that one-SD increases of circulating HSPCs frequency, serum CRP level, white blood cell count and neutrophil count were associated with $2.33 \%$ (95\% $\mathrm{CI},-4.61 \%$ to $-0.06 \%$; $\mathrm{p}=0.045), 3.04 \%(95 \% \mathrm{CI},-5.65 \%$ to $-0.44 \% ; \mathrm{p}=0.023), 1.92 \%(95 \% \mathrm{CI},-3.28 \%$ to $-0.56 \% ; \mathrm{p}=0.007)$ and $2.25 \%(95 \% \mathrm{CI},-3.58 \%$ to $-0.09 \% ; \mathrm{p}=0.01)$ declines of left ventricular ejection fraction in CHD patients, respectively. Furthermore, one-SD increases of circulating HSPCs frequency, white blood cell count and neutrophil count were associated with $2.42 \mathrm{~mm}(95 \% \mathrm{CI}, 0.03-2.93 \mathrm{~mm} ; \mathrm{p}=0.045), 1.12 \mathrm{~mm}$ $(0.23-2.01 \mathrm{~mm} ; \mathrm{p}=0.013)$ and $1.23 \mathrm{~mm}(95 \% \mathrm{CI}, 0.38-2.09 \mathrm{~mm} ; \mathrm{p}=0.004)$ increases of end-systolic diameter in the left ventricle in CHD patients, respectively. By contrast, CRP was not associated with end-systolic diameter in the left ventricle $(p=0.26)$. Moreover, LDL-c was associated with neither ejection fraction nor end-systolic diameter ( $\mathrm{p} \geq 0.19$ ). Bonferroni correction of 16 biomarkers did not identify any significant association between any biomarker and cardiac function studied.

Besides the biomarkers mentioned above, conventional cardiac injury markers including serum creatinine, brain natriuretic peptide (NT-pro-BNP), lactic dehydrogenase (LDH), $\alpha$-hydroxybutyrate dehydrogenase $(\mathrm{HBDH})$ and cardiac troponin I (TnI) were included individually in the analysis ${ }^{18,19}$. Serum creatinine and serum lactic dehydrogenase were negatively associated with ejection fraction and positively associated with end-systolic diameter of the left ventricle in CHD patients. Nevertheless, none of the biomarkers was associated with end-dilation diameter of the left ventricle in the patients after adjusting for covariables $(\mathrm{p} \geq 0.12)$. Figure 5 shows the $-\log 10(P)$ probability plot of the multivariable-adjusted association of various markers with ejection fraction (continuous) or end-systolic diameter (continuous) of the left ventricle in CHD patients.

\section{Discussion}

The key findings of this study can be summarised as follows. (1) HSPCs frequency in the peripheral blood was 1.8-fold higher in CHD patients than in non-CHD participants. (2) By multivariate-adjusted logistic analysis, per one-SD increase for each of the following variables, the odds ratio of having CHD vs. not having it was 1.24 for HSPCs $(p=0.017), 1.48$ for CRP $(p<0.0001), 1.22$ for white blood cell count $(p=0.043)$ and 1.33 for LDL-c 


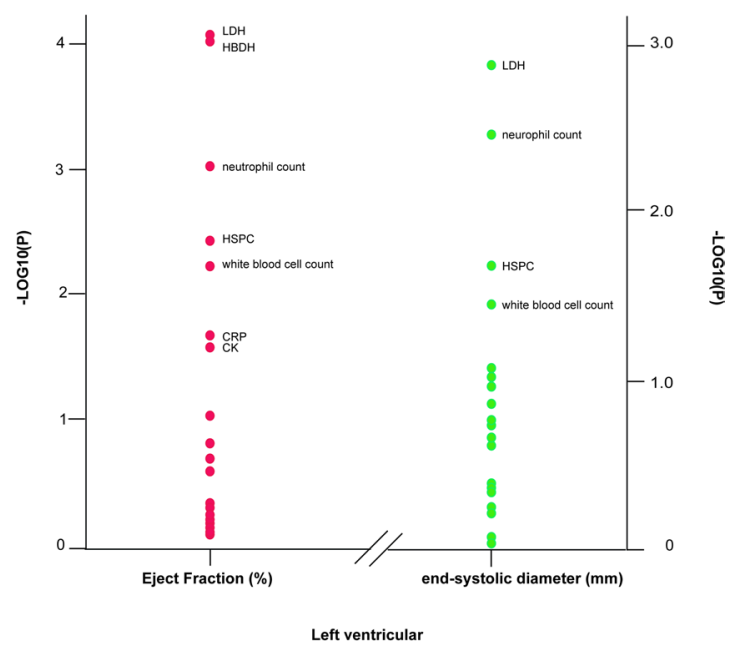

Figure 5. $-\log 10(\mathrm{p})$ probability plot of the multivariable-adjusted associations of various indexes of left ventricular function with the biomarkers. $-\log 10(\mathrm{p})$ probability plot of the multivariable-adjusted associations of various indexes of left ventricular function with the biomarkers in CHD patients. All analyses were adjusted for covariables, including age, sex, mean arterial pressure, heart rate, plasma glucose, serum creatinine, plasma glucose, $\gamma$-glutamyltransferase, smoking, alcohol intake, history of hypertension ( 1 or 0$)$, history of diabetes ( 1 or 0 ), use of diuretics, inhibitors of the renin-angiotensin system ( $\beta$-blockers, angiotensin-converting-enzyme inhibitors and angiotensin type1 receptor blockers), vasodilators (calcium-channel blockers and $\alpha$-blockers), metformin and statins. With the exceptions of LDL-c and HDL-c, all other biomarkers were additionally adjusted with total-to-HDL-c ratio. Biomarkers in Fig. 3 as well as creatinine kinase (CK), brain natriuretic peptide (NT-pro-BNP), lactic dehydrogenase (LDH), $\alpha$-hydroxybutyrate dehydrogenase $(\mathrm{HBDH})$ and cardiac troponin I (TnI) were analysed and those with $\mathrm{p}<0.05$ are named here.

$(\mathrm{p}=0.002)$. (3) Likewise, in CHD patients, per one-SD increase for each of the following variables, the odds ratio of having one coronary artery stenosis $\geq 70 \%$ vs. $<70 \%$ was 1.72 for HSPCs $(p=0.006), 1.37$ for CRP $(p=0.17)$, 1.56 for white blood cell count $(\mathrm{p}=0.09)$ and 2.08 for LDL-c $(\mathrm{p}=0.009)$. For CHD patients, per one-SD increase of each variable, the odds ratio of having mild vs. severe coronary stenosis was 2.08 for HSPCs $(\mathrm{p}=0.0009), 1.67$ for CRP $(\mathrm{p}=0.026)$, and 1.67 for LDL-c $(\mathrm{p}=0.014)$. (4) HSPCs frequency, white blood cell count and CRP level discriminated coronary occlusion $<70 \%$ vs. $\geq 70 \%$ with comparable potency. (5) By multivariate-adjusted linear regression analysis, circulating HSPCs frequency, white blood cell count and neutrophil count were inversely correlated with left ventricular ejection fraction and positively correlated with end-systolic diameter of the left ventricle in CHD patients. CRP was negatively associated with ejection fraction but not related to end-systolic diameter of the left ventricle in the patients. And (6) After Bonferroni correction for 16 biomarkers, CRP and HSPCs remained significantly associated with the odd ratio of having CHD vs. no CHD and mild vs. severe coronary stenosis, respectively.

Atherosclerosis is the underlying pathogenesis of $\mathrm{CHD}$ and contributes substantially to cardiac dysfunction and disease progression. Inflammatory cells and pro-inflammatory cytokine and chemokine production from inflammatory cells are hallmarks of atherosclerotic plaque ${ }^{10-12}$. The evolution of early/stable plaque to advanced/ vulnerable plaque results from a phenotypic transition from controlled to uncontrolled inflammation ${ }^{3}$. HSPCs give rise to all types of blood cells and are the source of inflammatory cells. They could thus be an important biomarker and intervention target for atherosclerosis.

This study on CHD patients was prompted in part by previous observations that hypercholesterolemia induced by a high-fat diet enhanced the proliferation of HSPCs and their subsequent differentiation to myeloid cells, including neutrophils, whereas the control of HSPCs proliferation and differentiation reversed hypercholesterolemia-induced leukocytosis and reduced atherosclerosis plaque in mice ${ }^{13,15}$. In this study, we reported that circulating HSPCs frequency was tightly associated with coronary stenoses in CHD patients. Compared with CRP, the conventional biomarker of coronary stenosis ${ }^{20}$, HSPCs is more sensitive in assessing the progression from mild stenosis $(<70 \%)$ to medium stenosis $(\geq 70 \%)$ and reflecting left ventricular end-systolic diameter in CHD patients. We further applied a correction for multiple testing for all the biomarkers studied ${ }^{21}$. By Bonferroni correction, HSPCs remained the only marker that was associated with odds ratio of having mild $v s$. severe coronary stenosis in CHD patients.

GM-CSF and SDF-1 $\alpha$ trigger HSPCs mobilisation from bone marrow to peripheral blood ${ }^{22-24}$. Moreover, a positive correlation between serum levels of SDF-1 1 and coronary artery occlusion was reported in CHD patients $^{25}$. In parallel with this, when atheroma cell suspension was obtained from carotid artery, GM-CSF levels were higher in patients with symptomatic plaque than in those with asymptomatic plaque ${ }^{26}$. In this study, we performed a detailed dissection of the relationships between GM-CSF, SDF-1 $\alpha$, HSPCs and coronary stenosis. Circulating HSPCs frequency was found to be positively associated with serum levels of GM-CSF $(r=0.12$, $\mathrm{p}=0.011)$ but not with SDF- $1 \alpha(\mathrm{r}=0.02, \mathrm{p}=0.61)$. Unlike HSPCs, neither GM-CSF nor SDF-1 $\alpha$ was associated 
with the severity of coronary stenosis in CHD patients. These findings indicate that GM-CSF partially contributed to the increase in HSPCs in the blood. GM-CSF and SDF-1 $\alpha$ appear to have weak effects on coronary occlusion.

Decreasing LDL-c and elevating HDL-c have been therapeutic targets for attenuating atherosclerosis and treating ischemic heart disease for decades. Recently, meta-analysis of multiple statin trials elegantly demonstrated the beneficial effects of statins in lowering LDL-c and reducing cardiovascular risks ${ }^{27,28}$. Proprotein convertase subtilisin-kexin type 9 (PCSK9) inhibitors are another drug family that can reduce LDL-c. Inhibition of PCSK9 abrogates LDL-receptor degradation and thus enhances LDL uptake for clearance ${ }^{29}$. PCSK9 inhibitors have also been shown to lead to a $60 \%$ reduction in LDL-c without any indication of side effects ${ }^{30,31}$. In the current study, we illustrated that LDL-c was increased in CHD patients and positively associated with atherosclerosis-based coronary stenosis even after adjusting for statins and other potential covariables. Our data are in line with other studies supporting the concept that LDL-c is an appropriate target for cardiovascular disease treatment. Paradoxically, a Mendelian randomisation study involving 111,194 individuals from two prospective general populations reported that a low LDL-c level due to genetic variation in PCSK9 and HMGCR is associated with a high risk of neurocognitive diseases including Alzheimer's disease and Parkinson's disease ${ }^{32}$. Therefore, there is a need for further investigation of the optimal therapeutic range of LDL-c for treating cardiovascular disease and protecting against adverse neurocognitive events.

Atherothrombosis is another major cause of coronary occlusion. D-dimer is a product of the degradation of cross-linked fibrin and is thus commonly used as a marker to predict plaque severity based on the Gensini score $^{33}$. In the current study, despite the extensive administration of anti-coagulation drugs, serum D-dimer and fibrinogen did not differ between subjects with and without CHD. In addition, none of these variables had any significant association with the severity of coronary stenosis in CHD patients.

The present study should be interpreted in consideration of its limitations. First, this is a cross-sectional study. Whether HSPCs could predict the outcome of adverse cardiovascular events or the incidence of CHD remains to be proven in longitudinal studies. Recently, Hammadah measured CD $34^{+}$cells in CHD patients and found that their low levels in circulation independently predict adverse cardiovascular disease outcomes ${ }^{34}$. A follow-up study of these patients would provide a better understanding of the role of HSPCs in cardiovascular disease outcomes. Second, we did not categorise monocytes into M1 and M2 subtypes or other subgroups. Third, we could not rule out the possibility that the increased HSPCs frequency in peripheral blood was derived from increased HSPCs proliferation or mobilisation from bone marrow into circulation. Fourth, we did not have data on the body mass of the subjects because, when most of them arrived, it was an emergency situation. As we included extensive covariables for adjustment, the impact of body mass index on the analysis should have been limited.

In conclusion, we identified HSPCs as an important marker to assess atherosclerosis-induced coronary stenosis. The level of circulating HSPCs increases in association with the occurrence of CHD and is significantly associated with the progression of mild coronary occlusion to a severe state. The increase of HSPCs in CHD patients has an adverse impact on ejection fraction and is positively associated with end-systolic diameter in the left ventricle. Further studies are required to testify whether HSPCs could be as a novel intervention target for CHD patients.

\section{Methods}

Subjects. All study procedures complied with the Declaration of Helsinki regarding investigations of human subjects. They received ethical approval from the institutional review boards of both Lu He Hospital and Capital Medical University. All participants provided written informed consent.

From March 2016 to May 2017, 556 patients were enrolled in this study. Their blood pressure was recorded as the mean of three readings and the mean arterial pressure was determined as diastolic pressure plus one-third of pulse pressure. Hypertension was defined as blood pressure of at least $140 \mathrm{mmHg}$ systolic or $90 \mathrm{mmHg}$ diastolic or the use of antihypertensive drugs. Diabetes was defined as plasma glucose of at least $7.0 \mathrm{mmol} / \mathrm{L}$ while fasting or of $11.0 \mathrm{mmol} / \mathrm{L}$ or more $2 \mathrm{~h}$ after an orally administered glucose load of $75 \mathrm{~g}$. Additional characteristics including age, medical history, smoking and drinking habits, and intake of medications were also recorded.

We excluded 88 patients because of no coronary angiography having been performed $(n=40)$, lack of FACS-based HSPC data $(n=29)$, missing basic information $(n=18)$ or values exceeding the mean by three standard deviations (SDs) or more $(\mathrm{n}=1)$. Thus, in total, 468 participants were statistically analysed. Among these CAD patients, 344 were examined by echocardiography. A flowchart of the study is presented in Fig. 1.

Echocardiography. Echocardiography was performed prior to coronary artery angiography. A single observer performed the echocardiography using a Philips iE33 (Philips, Amsterdam, Netherlands) device and analysed the digitally stored images, averaging three heart cycles, using a workstation running Hina Uses Workstation (version 2.0; Hina, China). Analyses of the echocardiography images were performed by an investigator who was blinded to the identity of the specific groups. Briefly, diastolic left ventricular (LV) function included the peak early (E) and late (A) diastolic velocities and flow duration from the transmitral blood flow Doppler signal, together with left ventricular ejection fraction (LVEF), left ventricular end-diastolic diameter, left ventricular end-systolic diameter, interventricular septal thickness, ventricular septal amplitude, and left ventricular volume including end-systolic volume (ESV) and end-diastolic volume (EDV). LVEF was calculated as follows:

$$
\mathrm{LVEF}=(\mathrm{EDV}-\mathrm{ESV}) / \mathrm{EDV} \times 100 \%
$$

Coronary angiography. The patients were examined by computed tomography (CT)-based coronary angiography in accordance with standard criteria (Philips FD10, the Netherlands). The stenoses in the left main coronary artery, anterior descending branch, left circumflex and right coronary artery were evaluated by two 
experienced cardiologists who were blinded to the group randomisation. In cases of disagreement, consensus was reached by further joint reading.

Biochemical measurement. After overnight fasting, venous blood samples were drawn for measurement of the total and differential white blood cell counts, serum total cholesterol, HDL cholesterol, triglycerides, creatinine, $\mathrm{D}$-dimer, C-reactive protein (CRP), plasma glucose and $\gamma$-glutamyltranspeptidase. Estimated glomerular filtration rate (eGFR) was derived from serum creatinine using the Chronic Kidney Disease Epidemiology Collaboration (CKD-EPI) equation ${ }^{35}$. LDL cholesterol (LDL-c) was computed from serum total and HDL cholesterol (HDL-c) and serum triglycerides by the Friedewald equation ${ }^{36}$. Participants were classified as having dyslipidaemia if at least one of the following criteria was met: total cholesterol higher than $4.9 \mathrm{mmol} / \mathrm{L}$, LDL cholesterol exceeding $3 \mathrm{mmol} / \mathrm{L}$, triglycerides higher than $1.7 \mathrm{mmol} / \mathrm{L}$ or HDL cholesterol less than $1.2 \mathrm{mmol} / \mathrm{L}$ in women and $1 \mathrm{mmol} / \mathrm{L}$ in $\mathrm{men}^{37}$. Serum creatinine, high-sensitive C-reactive protein (CRP), cardiac creatinine, lactic dehydrogenase $(\mathrm{LDH}), \alpha$-hydroxybutyrate dehydrogenase $(\mathrm{HBDH})$ and cardiac troponin $\mathrm{I}(\mathrm{TnI})$ were measured in the central laboratory at Lu He Hospital.

Colony-forming assays. Mononuclear cells in peripheral blood were stained with an antibody cocktail against lineage, CD34, CD45RA and CD38. $\mathrm{Lin}^{-} \mathrm{CD} 34^{+} \mathrm{CD} 38^{-} \mathrm{CD} 45 \mathrm{RA}^{\mathrm{dim}}$ cells were sorted by FACS and plated with Methocult H4434 (Stem Cell Technologies, Vancouver, Canada). After 10-14 days, colonies were assessed under a light microscope. To confirm the lineages of cells in generated colonies, cells were harvested and stained with anti-human CD11b for FACS analysis.

Flow cytometry. HSPCs constitute a tiny population among white blood cells. Therefore, to achieve reliable analysis, mononuclear cells were isolated from peripheral blood by Ficoll-based density gradient centrifugation, as described previously ${ }^{16}$. After isolation, cells were stained with an antibody cocktail containing anti-human lineage cocktail APC (BD), anti-human CD38 APC (eBioscience), anti-human CD34PE (eBioscience) and anti-human CD45RA PerCP-Cy5.5 (eBioscience). Dead cells were excluded by their size forward scatter (FSC) and side scatter (SSC) and staining of 7-AAD. Cells stained with isotype antibodies or unstained cells were used as a negative control for FACS analysis. At least 100,000 events were acquired for FACS analysis. Data were acquired using a FACS Canto (BD) and analysed by FlowJo. HSPCs, defined as $\mathrm{Lin}^{-} \mathrm{CD} 34^{+} \mathrm{CD} 38^{-} \mathrm{CD} 45 \mathrm{RA}{ }^{\mathrm{dim}}$ cells, were counted. The frequency of HSPCs among mononuclear cells was calculated.

Enzyme-linked immunosorbent assay. The concentrations of serum N-terminal pro-B-type natriuretic peptide (NT-pro-BNP), stromal-derived factor $1 \alpha$ (SDF-1 $\alpha$ ), granulocyte-macrophage colony stimulating factor (GM-CSF), apolipoprotein A-1 (apoA-1), apolipoprotein B (apoB) and D-dimer were measured by ELISA, in accordance with the manufacturer's instructions (MLBio, Shanghai, China). Intra-assay coefficients of variation for NT-pro-BNP, SDF-1a, GM-CSF, apoA-1 and apoB were $0.25 \%, 0.29 \%, 0.48 \%, 0.27 \%$ and $0.59 \%$, while inter-assay ones were $1.99 \%, 4.93 \%, 4.81 \%, 3.13 \%$ and $3.73 \%$, respectively.

Statistical analysis. For database management and statistical analysis, we used the SAS system, version 9.4 (SAS Institute Inc., Cary, NC, USA). We normalised the distributions of $\gamma$-glutamyltransferase, HSPC, serum creatinine, serum triglyceride, fibrinogen and D-dimer by logarithmic transformation. Means were compared using $t$-test or ANOVA and proportions by Fisher's exact test. Pearson's correlation was used for single association analysis. For $t$-test, ANOVA, proportions by Fisher's exact test and Pearson's correlation, a p-value $<0.05$ was considered statistically significant.

Subjects with coronary artery stenosis $\geq 50 \%$ were diagnosed as having CHD. The extent of CHD was further categorised into mild, intermediate and severe groups using the following criteria: all stenosis $<70 \%$, one coronary artery stenosis $\geq 70 \%$ or more than one coronary artery stenosis $\geq 70 \%$, respectively. Thereafter, multivariate-adjusted logistic analysis was performed to evaluate the coronary occlusion severity with each marker independently. The importance of each marker with its association to coronary stenoses $(\geq 70 \%$ vs. $<70 \%)$ ) was assessed from the Variable Importance in Projection (VIP) scores of Wold in all study subjects following construction of the partial least square (PLS) factors. We further evaluated the potential of CRP, circulating HSPCs, white blood cell count and LDL-c to discriminate between CHD patients and controls with coronary stenosis $\geq 70 \%$ vs. $<70 \%$ by constructing receiver operating characteristic (ROC) curves and by calculating the area under them (AUC). The $95 \%$ confidence interval $(95 \% \mathrm{CI})$ of the AUC was calculated by the DeLong method.

Multivariate-adjusted linear regression analysis was performed for the regression of LV function against each marker in CHD patients. While accounting for covariables, we performed regression of the indexes of diastolic LV function on the markers and constructed - $\log 10$ probability plots. Bonferroni correction was applied for variants (i.e. biomarkers) that were associated with coronary stenosis or cardiac function index. A P value $<0.0031$ $(0.05 / 16)$ was considered statistically significant. In this study, all analyses included adjustments for covariables, including age, sex, mean arterial pressure, heart rate, plasma glucose, serum creatinine, plasma glucose, $\gamma$-glutamyltransferase, smoking, alcohol intake, history of hypertension ( 1 or 0$)$, history of diabetes ( 1 or 0$)$, use of diuretics, inhibitors of the renin-angiotensin system ( $\beta$-blockers, angiotensin-converting-enzyme inhibitors and angiotensin type-1 receptor blockers), vasodilators (calcium-channel blockers and $\alpha$-blockers), metformin and statins. With the exceptions of LDL-c and HDL-c, all other biomarkers were additionally adjusted for using the total-to-HDL-cholesterol ratio. 


\section{Data Availability}

The corresponding author will make anonymized data available to researchers who present an outstanding research plan that will move the field forward.

\section{References}

1. Daugherty, A., Tabas, I. \& Rader, D. J. Accelerating the pace of atherosclerosis research. Arterioscler Thromb. Vasc. Biol. 35, 11-12 (2015).

2. Weber, C., Badimon, L., Mach, F. \& Van der Vorst, E. Therapeutic strategies for atherosclerosis and atherothrombosis: Past, present and future. Thromb. Haemost. 117, 1258-1264 (2017).

3. Fredman, G. \& Tabas, I. Boosting Inflammation Resolution in Atherosclerosis: The Next Frontier for Therapy. Am. J. Pathol. 187, 1211-1221 (2017).

4. Nowak, W. N., Deng, J., Ruan, X. Z. \& Xu, Q. Reactive Oxygen Species Generation and Atherosclerosis. Arterioscler. Thromb. Vasc. Biol. 37, 41-52 (2017).

5. Xu, L. et al. Foamy monocytes form early and contribute to nascent atherosclerosis in mice with hypercholesterolemia. Arterioscler. Thromb. Vasc. Biol. 35, 1787-1797 (2015).

6. Westerterp, M. et al. Deficiency of ATP-Binding Cassette Transporters A1 and G1 in Endothelial Cells Accelerates Atherosclerosis in Mice. Arterioscler. Thromb. Vasc. Biol. 36, 1328-1337 (2016).

7. Marsch, E. et al. Deficiency of the oxygen sensor prolyl hydroxylase 1 attenuates hypercholesterolaemia, atherosclerosis, and hyperglycaemia. Eur. Heart. J. 37, 2993-2997 (2016).

8. Braamskamp, M. et al. Effect of Rosuvastatin on Carotid Intima-Media Thickness in Children with Heterozygous Familial Hypercholesterolemia: The CHARON Study (Hypercholesterolemia in Children and Adolescents Taking Rosuvastatin Open Label). Circulation. 136, 359-366 (2017).

9. Kiss, L. Z. et al. Signs of subclinical atherosclerosis in asymptomatic patients at increased risk of type 2 diabetes mellitus. J. Diabetes. Complications. 31, 1293-1298 (2017).

10. Sanad, E. F., Hamdy, N. M., El-Etriby, A. K., Sebak, S. A. \& El-Mesallamy, H. O. Peripheral leucocytes and tissue gene expression of granzyme B/perforin system and serpinB9: Impact on inflammation and insulin resistance in coronary atherosclerosis. Diabetes. Res. Clin. Pract. 131, 132-141 (2017).

11. Bentzon, J. F. Targeting Inflammation in Atherosclerosis. J. Am. Coll. Cardiol. 68, 2794-2796 (2016).

12. van der Valk, F. M. et al. In vivo imaging of enhanced leukocyte accumulation in atherosclerotic lesions in humans. J. Am Coll Cardiol. 64, 1019-1029 (2014).

13. Murphy, A. J. et al. ApoE regulates hematopoietic stem cell proliferation, monocytosis, and monocyte accumulation in atherosclerotic lesions in mice. J. Clin. Invest. 121, 4138-4149 (2010).

14. Tall, A. R. \& Yvan-Charvet, L. Cholesterol, inflammation and innate immunity. Nat. Rev Immunol. 15, 104-116 (2015).

15. Feng, Y. et al. Hematopoietic stem/progenitor cell proliferation and differentiation is differentially regulated by high-density and low-density lipoproteins in mice. PLoS One 7, e47186 (2012).

16. Gao, M. et al. Regulation of high-density lipoprotein on hematopoietic stem/progenitor cells in atherosclerosis requires scavenger receptor type BI expression. Arterioscler. Thromb. Vasc. Biol. 34, 1900-1909 (2014).

17. Wong, W. M. et al. Expression of integrin alpha2 receptor in human cord blood CD34+CD38-CD90+ stem cells engrafting longterm in NOD/SCID-IL2Rgamma(c) null mice. Stem. Cells. 31, 360-371 (2013).

18. Newby, L. K. \& Ohman, E. M. Biomarkers: Troponin testing-risk stratification to stratified medicine. Nat. Rev. Cardiol. 12, 625-626 (2015).

19. Smedsrud, M. K. et al. Sensitive cardiac troponins and N-terminal pro-B-type natriuretic peptide in stable coronary artery disease: correlation with left ventricular function as assessed by myocardial strain. Int. J. Cardiovasc. Imaging. 31, 967-973 (2015).

20. Poredos, P., Spirkoska, A., Lezaic, L., Mijovski, M. B. \& Jezovnik, M. K. Patients with an Inflamed Atherosclerotic Plaque have Increased Levels of Circulating Inflammatory Markers. J. Atheroscler. Thromb. 24, 39-46 (2017).

21. Yang, Q. et al. ANGPTL4 variants and their haplotypes are associated with serum lipid levels, the risk of coronary artery disease and ischemic stroke and atorvastatin cholesterol-lowering response. Nutr Metab. 15, 70 (2018).

22. Lonial, S. et al. Mobilization of hematopoietic progenitors from normal donors using the combination of granulocyte-macrophage colony-stimulating factor and granulocyte colony-stimulating factor results in fewer plasmacytoid dendritic cells in the graft and enhanced donor T cell engraftment with Th1 polarization: results from a randomized clinical trial. Biol. Blood. Marrow. Transplant. 19, 460-467 (2013).

23. Mendt, M. \& Cardier, J. E. Role of SDF-1 (CXCL12) in regulating hematopoietic stem and progenitor cells traffic into the liver during extramedullary hematopoiesis induced by G-CSF, AMD3100 and PHZ. Cytokine. 76, 214-221 (2015).

24. Khurana, S. et al. SMAD signaling regulates CXCL12 expression in the bone marrow niche, affecting homing and mobilization of hematopoietic progenitors. Stem. Cells. 32, 3012-3022 (2014).

25. Tavakolian, F. V. et al. Serum CXCL10 and CXCL12 chemokine levels are associated with the severity of coronary artery disease and coronary artery occlusion. Int. J. Cardiol. 233, 23-28 (2017).

26. Shalhoub, J. et al. Multi-analyte profiling in human carotid atherosclerosis uncovers pro-inflammatory macrophage programming in plaques. Thromb. Haemost. 115, 1064-1072 (2016).

27. Preiss, D. et al. Risk of incident diabetes with intensive-dose compared with moderate-dose statin therapy: a meta-analysis. JAMA. 305, 2556-2564 (2011).

28. Boekholdt, S. M. et al. Very low levels of atherogenic lipoproteins and the risk for cardiovascular events: a meta-analysis of statin trials. J. Am. Coll. Cardiol. 64, 485-494 (2014).

29. Cohen, J. et al. Low LDL cholesterol in individuals of African descent resulting from frequent nonsense mutations in PCSK9. Nat. Genet. 37, 161-165 (2005).

30. Robinson, J. G. \& Kastelein, J. J. PCSK9 Inhibitors and Cardiovascular Events. N. Engl. J. Med. 373, 774 (2015).

31. Zhang, X. L. et al. Safety and efficacy of anti-PCSK9 antibodies: a meta-analysis of 25 randomized, controlled trials. BMC. Med. 13, 123 (2015).

32. Benn, M., Nordestgaard, B. G., Frikke-Schmidt, R. \& Tybjaerg-Hansen, A. Low LDL cholesterol, PCSK9 and HMGCR genetic variation, and risk of Alzheimer's disease and Parkinson's disease: Mendelian randomisation study. BMJ. 357, 1648 (2017).

33. Gong, P. et al. Plasma d-Dimer as a Useful Marker Predicts Severity of Atherosclerotic Lesion and Short-Term Outcome in Patients With Coronary Artery Disease. Clin. Appl. Thromb. Hemost. 22, 633-640 (2016).

34. Hammadah, M. et al. Telomere Shortening, Regenerative Capacity, and Cardiovascular Outcomes. Circ. Res. 120, 1130-1138 (2017).

35. Levey, A. S. et al. A new equation to estimate glomerular filtration rate. Ann. Intern. Med. 150, 604-612 (2009).

36. Johnson., R., McNutt, P., MacMahon, S. \& Robson, R. Use of the Friedewald formula to estimate LDL-cholesterol in patients with chronic renal failure on dialysis. Clin. Chem. 43, 2183-2184 (1997).

37. Mancia, G. et al. 2013 ESH/ESC guidelines for the management of arterial hypertension: the Task Force for the Management of Arterial Hypertension of the European Society of Hypertension (ESH) and of the European Society of Cardiology (ESC). Eur. Heart. J. 34, 2159-2219 (2013). 


\section{Acknowledgements}

This work was supported by The National Science Funding in China (grant numbers 81470566 \& 81670765) to Ying-Mei Feng. Ying-Mei Feng had full access to all of the data of the study and takes responsibility for the integrity of the data and the accuracy of the data analysis.

\section{Author Contributions}

All authors contributed substantially to the study in the aspects of acquisition and/or interpretation of the data. Fu-Li Zhu, Ning-Zhang, Jing Yang, Wei-Ping Sun, Yi-Qing Shen, Yu-Mei Wen, Sha-Sha Yuan, Dong Zhao and Hai-Bin Zhang collected patient data; Ning-Zhang and Xiao-Juan Ma performed FACS experiments. Hai-Bin Zhang and Ying-Mei Feng initiated and designed the study. Ying-Mei Feng analysed the data and drafted the manuscript.

\section{Additional Information}

Competing Interests: The authors declare no competing interests.

Publisher's note: Springer Nature remains neutral with regard to jurisdictional claims in published maps and institutional affiliations.

(c) Open Access This article is licensed under a Creative Commons Attribution 4.0 International License, which permits use, sharing, adaptation, distribution and reproduction in any medium or format, as long as you give appropriate credit to the original author(s) and the source, provide a link to the Creative Commons license, and indicate if changes were made. The images or other third party material in this article are included in the article's Creative Commons license, unless indicated otherwise in a credit line to the material. If material is not included in the article's Creative Commons license and your intended use is not permitted by statutory regulation or exceeds the permitted use, you will need to obtain permission directly from the copyright holder. To view a copy of this license, visit http://creativecommons.org/licenses/by/4.0/.

(c) The Author(s) 2019 